\title{
Multicentre evaluation of the diagnostic value of cardiac troponin T, CK-MB mass, and myoglobin for assessing patients with suspected acute coronary syndromes in routine clinical practice
}

\author{
P O Collinson, P J Stubbs, A-C Kessler, for the Multicentre Evaluation of Routine \\ Immunoassay of Troponin T study (MERIT)
}

See end of article for authors' affiliations

Correspondence to: Dr Paul O Collinson, Department of Chemical Pathology, 2nd Floor Jenner Wing, St George's Hospital, Blackshaw Road, London SW17 OQT, UK; paul.collinson@ stgeorges.nhs.uk

Accepted 20 November 2002

\begin{abstract}
Objective: To assess the diagnostic efficiency of the third generation cardiac troponin T assay in routine clinical practice.

Design: Prospective observational study of unselected consecutive admissions.

Setting: Multicentre study in 43 teaching and non-teaching hospitals in 13 countries.

Subjects: 1105 hospital admissions, median age 67 years (range 15-96 years, $63.7 \%$ male) with suspected acute coronary syndromes $(72.3 \%$ of cases) or other non-specific symptoms where cardiac disease required exclusion $(27.7 \%)$.

Interventions: Over the study period, myoglobin, creatine kinase $M B$ isoenzyme (CK-MB), and cardiac troponin $\mathrm{T}$ where measured in parallel with conventional diagnostic tests. Final diagnostic classification involved standard ECG changes and CK-MB mass exceeding $5.0 \mathrm{\mu g} / \mathrm{l}$.

Main outcome measures: Diagnostic efficiency was assessed by receiver operator characteristic curve analysis including and excluding patients with unstable angina.

Results: Measurement of cardiac troponin T was diagnostically equivalent to CK-MB and both were better than myoglobin, with areas under the curve at 12 hours of $0.94,0.99$, and 0.80 , respectively. Diagnostic criteria using CK-MB were inadequate and showed bias when patients with unstable angina were included. Elevations of cardiac troponin T did not occur when cardiac disease could be categorically excluded but were found in clinical conditions other than suspected acute coronary syndromes. Conclusions: $C K-M B$ is unsuitable as a diagnostic gold standard even at the proposed lower threshold. A lower cut off for cardiac troponin T of $0.05 \mathrm{\mu g} / \mathrm{l}$ should be used for diagnosis of acute myocardial infarction. Diagnosis of acute myocardial infarction cannot be made solely on the basis of a cardiac troponin $\mathrm{T}$ result.
\end{abstract}

$\mathrm{T}$ he ECG is the diagnostic tool of first choice to select patients for thrombolysis ${ }^{12}$ but has a sensitivity of $55-75 \%$ for acute myocardial infarction. ${ }^{3-5}$ The majority of patients admitted with suspected acute coronary syndromes do not have ischaemic heart disease. Biochemical tests to exclude acute myocardial infarction are part of the routine investigation profile, with diagnosis defined by World Health Organization criteria. ${ }^{6}$ New standards for biochemical diagnosis have been proposed, incorporating myoglobin and the cardiac troponins $\mathrm{T}(\mathrm{cTnT})$ and I (cTnI) ${ }^{7-9}$ Myoglobin shows earlier rises than the $\mathrm{MB}$ isoenzyme of creatine kinase (CK-MB), ${ }^{10-12}$ and CTnT and CTnI are cardiospecific and have prognostic value. ${ }^{13-17} \mathrm{CK}-\mathrm{MB}$ by mass measurement is the best single test for the diagnosis of acute myocardial infarction by conventional WHO criteria. ${ }^{18-23}$ The use of either CK-MB mass or cTnT/cTnI above the 99th centile of a reference population has been proposed as the biochemical gold standard for acute myocardial infarction. ${ }^{7}$

Comparison of new tests with a diagnosis using CK-MB mass as the gold standard produces a paradox when markers with greater cardiospecificity are employed. They appear to have lower diagnostic efficiency. Outcome based studies has resolved this problem. There is already a large body of data based on conventional diagnostic criteria. Evaluation of cTnT (the putative gold standard) must therefore allow for imperfections in the current (CK-MB) based gold standard, but also be referenced to it. Analysis of a large, well categorised patient population including and excluding patients with unstable angina, combined with a rigorous diagnostic classification for acute myocardial infarction, will achieve this. This population must reflect the mixed chest pain population seen in routine clinical practice rather than a research setting with carefully selected patient groups.

We have undertaken a multicentre study of measurement using a real time immunoassay analyser. A large subject population was studied, including patients in whom nonspecific elevations of routinely used biochemical markers of myocardial damage can occur.

\section{METHODS}

Patient population

In order to reflect routine clinical practice there were no exclusion criteria, with the exception that all patients studied were consecutive admissions who had biochemical testing to confirm or exclude acute coronary syndrome as part of their routine diagnostic work up. All patients enrolled in the study were expected to have had adequate investigation (stress ECG, radionucleide cardiac imaging, cardiac catheterisation, ventilation-perfusion scans, pulmonary angiography, gastroduodenoscopy, and laboratory testing as clinically indicated and reflecting clinical practice in the participating institutions), to allow an accurate final diagnosis to be made. In addition, participating centres were encouraged to include patients within the study in whom conventional biochemical testing for myocardial damage was difficult but the 
cardiospecificity of cTnT measurement might be expected to confer an advantage (myositis, rhabdomyolysis, multiple trauma).

Data were recorded prospectively on all patients, using a structured proforma including relevant clinical details, ECG data, routine biochemical results with reference intervals, and final diagnosis. Care was taken to record the duration of chest pain before admission where possible. As timing of chest pain can be unreliable, time from admission to venepuncture was recorded in all cases and was used as the index time for assessment.

Data proformas were then independently reviewed centrally in a blinded fashion by two of the investigators (POC and PJS) to check whether the data were internally consistent and compatible with the diagnosis supplied. When there was a discrepancy, further information was obtained from the participating centre. Where a final diagnosis could not be agreed, third party adjudication was used to assign the case to the appropriate patient group.

In all, 1105 patients admitted to 44 hospitals in 13 countries with suspected acute coronary syndrome, or in whom acute coronary syndrome was considered as a secondary diagnosis, were enrolled in the study. Of these, 799 (72.3\%) had a primary diagnosis of suspected acute coronary syndrome, and $306(27.7 \%)$ had investigations for other reasons. The median age of the subjects was 67 years (range 15-96 years; lower quartile 57 , upper quartile 76$) ; 63.7 \%$ of the patients were male, median age 66 years (range $15-96$ years; lower quartile 53.5, upper quartile 74 ), and $36.3 \%$ were female, median age 72 years (range 27-96 years, lower quartile 63, upper quartile 80 ). The median duration of chest pain was 3.9 hours (range very short to 12.5 hours).

\section{Diagnostic categorisation}

In order to allow comparison with previous studies, final diagnostic categorisation of patients on hospital discharge was made using WHO criteria for ischaemic heart disease but with CK-MB mass as the biochemical gold standard.

Acute myocardial infarction was diagnosed when there were characteristic ECG changes-either ST segment elevation or the development of new Q waves-confirmed by significant changes in serial cardiac enzymes. ST segment elevation was judged to be present if it was $\geqslant 0.1 \mathrm{mV}$ at the $\mathrm{J}$ point in one or more extremity leads or $\geqslant 0.2 \mathrm{mV}$ in one or more precordial leads. Significant changes in cardiac enzymes were considered to occur when creatine kinase exceeded twice the upper reference limit of the local laboratory, or if CK-MB mass exceeded $5 \mu \mathrm{g} / \mathrm{l}$.

Unstable angina pectoris was diagnosed in patients with an episode of chest pain within the previous 48 hours and without characteristic ECG changes (ST segment elevation as defined above or development of new Q waves), who had non-specific ECG changes (ST depression or T wave inversion) or continuing chest pain with or without non-specific ECG changes and without significant changes in cardiac enzymes.

Stable angina pectoris was diagnosed in patients with known ischaemic heart disease but without acute chest pain and without significant changes in cardiac enzymes.

Non-ischaemic chest pain was diagnosed when follow up investigations allowed coronary artery disease to be excluded or when a definite source of non-cardiac chest pain could be identified.

Other diagnostic groups were taken from the final discharge diagnosis where a positive diagnosis could be made and ischaemic heart disease excluded.

\section{Analytical methods}

Blood samples for measurement of CTnT, CK-MB mass, and myoglobin were drawn along with blood for routine investigations according to the local investigation protocol. The choice of the use of serum or plasma was left to the local participating centre. For serum, blood samples were taken, allowed to clot fully, and then centrifuged. For plasma, blood samples were taken, mixed by inversion, and then centrifuged. Plasma or serum samples (as appropriate) were then separated for analysis by the laboratory for CTnT, CK-MB mass, and myoglobin determinations. Measurement of other cardiac enzymes in the local laboratories were done by automated analysis according to the manufacturers' recommended methods.

Measurements of cTnT, myoglobin, and CK-MB mass were done using an Elecsys analyser by the troponin T STAT third generation, myoglobin STAT, and CK-MB STAT methods (Roche Diagnostics, Tutzing, Germany). These assays are based on electrochemiluminescence immunoassay technology (ECLIA) using two mouse monoclonal antibodies in a sandwich format, two step assay. They were done on Elecsys 1010 and 2010 immunoassay analysers according to the manufacturer's instructions. For CTnT, the detection limit was $0.01 \mu \mathrm{g} / \mathrm{l}$ with an upper limit of $25 \mu \mathrm{g} / \mathrm{l}$; for $\mathrm{CK}-\mathrm{MB}$ the detection limit was $0.1 \mu \mathrm{g} / \mathrm{l}$ with an upper limit of $500 \mu \mathrm{g} / \mathrm{l}$; and for myoglobin, the detection limit was $15 \mu \mathrm{g} / \mathrm{l}$ with an upper limit of $3000 \mu \mathrm{g} / \mathrm{l}$. The analytical performance of the assays was good, with total imprecision less than $10 \%$ in, respectively, $97 \%$ (cTnT, range $0.15-5.77 \mu \mathrm{g} / \mathrm{l}$ ), $94 \%$ (CK-MB, range $5.95-53 \mu \mathrm{g} / \mathrm{l}$ ), and $97 \%$ (myoglobin, 90.4-1133 $\mu \mathrm{g} / \mathrm{l}$ ) of participating centres.

\section{Data handling and statistical methods}

Parametric statistics were used for the derivation of all estimates of imprecision. Baseline demographics are expressed as medians and range, with upper and lower quartiles where appropriate. Diagnostic performance was assessed by construction of receiver operating characteristic (ROC) curves with areas compared for significance at the $p=0.05$ level by the normal approximation method (as the numbers were large). All statistical analysis was done using the SAS statistical package (SAS Institute Inc, Cary, North Carolina, USA). It has been documented that when diagnosis is based on creatine kinase and CK-MB, an elevation of cTnT is seen in approximately $33 \%$ of patients with unstable angina ${ }^{15}$; thus the effect of variation in the diagnostic categorisation on the underlying population was studied by doing an ROC analysis including and excluding patients with a final diagnosis of unstable angina.

\section{RESULTS \\ Patients with a primary diagnosis of suspected acute coronary syndrome}

In all, 799 patients were studied: 467 with acute myocardial infarction, 164 with unstable angina, 100 with stable angina, and 68 with non-ischaemic chest pain. The data from the ROC analysis are summarised in table 1 .

When patients with unstable angina were excluded, measurement of cTnT in samples taken less than two hours from admission was better than either myoglobin or CK-MB mass. Measurement of cTnT was significantly better than myoglobin $(\mathrm{p} \leqslant 0.05)$ at all other time points, most notably at 12-24 hours from admission. CK-MB and cTnT showed equivalent diagnostic efficiency at between 2-6 hours and at all time points thereafter. Inclusion of patients with unstable angina resulted in an apparent fall in the diagnostic efficiency of both myoglobin and cTnT. At less than 2 hours, 2-6 hours, and 6-12 hours, CK-MB was better than CTnT, but diagnostic efficiencies converged at 12-24 hours from admission. CK-MB was superior to myoglobin at all time points. Myoglobin and cTnT showed comparable diagnostic efficiencies until 6-12 hours from admission, when there was a progressive decrease in the efficiency of myoglobin but an increase in the value for cTnT. The ROC curves are shown in figs 1 and 2.

The third generation assay has both an improved imprecision profile and a lower detection limit. A detailed evaluation of the ROC curve was therefore performed. The clinical 
Table 1 Areas under receiver operating characteristic curves including and excluding patients with unstable angina

\begin{tabular}{|c|c|c|c|c|c|c|c|}
\hline \multirow[b]{3}{*}{ Population } & \multirow[b]{3}{*}{ Time (hours) } & \multicolumn{6}{|c|}{ Area under the ROC curve (confidence intervals in parentheses) } \\
\hline & & \multicolumn{2}{|c|}{ Troponin T } & \multicolumn{2}{|c|}{ Myoglobin } & \multicolumn{2}{|c|}{ CK-MB mass } \\
\hline & & $\mathrm{n}$ & AUC & $\mathrm{n}$ & AUC & $\mathrm{n}$ & AUC \\
\hline $\mathrm{Ml} / \mathrm{NICP}+\mathrm{SAP}$ & $<2$ & 461 & $0.93(0.74$ to 1.00$)$ & 364 & $0.81(0.61$ to 1.00$)$ & 245 & $0.85(0.64$ to 1.00$)$ \\
\hline $\mathrm{MI} / \mathrm{NICP}+\mathrm{SAP}$ & 2 to $<6$ & 296 & $0.96(0.77$ to 1.00$)$ & 254 & $0.91(0.71$ to 1.00$)$ & 203 & $0.93(0.68$ to 1.00$)$ \\
\hline $\mathrm{MI} / \mathrm{NICP}+\mathrm{SAP}$ & 6 to $<12$ & 349 & $0.98(0.79$ to 1.00$)$ & 293 & $0.89(0.68$ to 1.00$)$ & 242 & $0.96(0.76$ to 1.00$)$ \\
\hline $\mathrm{MI} / \mathrm{NICP}+\mathrm{SAP}$ & 12 to $<24$ & 332 & $0.98(0.80$ to 1.00$)$ & 251 & $0.85(0.65$ to 1.00$)$ & 213 & $0.98(0.75$ to 1.00$)$ \\
\hline $\mathrm{MI} / \mathrm{NICP}+\mathrm{SAP}+\mathrm{UAP}$ & $<2$ & 746 & $0.78(0.66$ to 0.91$)$ & 624 & 0.75 (0.61 to 0.89$)$ & 295 & 0.85 (0.65 to 1.00$)$ \\
\hline $\mathrm{MI} / \mathrm{NICP}+\mathrm{SAP}+\mathrm{UAP}$ & 2 to $<6$ & 681 & $0.86(0.69$ to 1.00$)$ & 514 & $0.87(0.68$ to 1.00$)$ & 253 & $0.93(0.68$ to 1.00$)$ \\
\hline $\mathrm{MI} / \mathrm{NICP}+\mathrm{SAP}+\mathrm{UAP}$ & 6 to $<12$ & 734 & $0.92(0.76$ to 1.00$)$ & 553 & $0.84(0.67$ to 1.00$)$ & 292 & $0.96(0.76$ to 1.00$)$ \\
\hline $\mathrm{MI} / \mathrm{NICP}+\mathrm{SAP}+\mathrm{UAP}$ & 12 to $<24$ & 717 & 0.94 (0.78 to 1.00$)$ & 511 & 0.80 (0.61 to 0.99$)$ & 263 & $0.99(0.75$ to 1.00$)$ \\
\hline
\end{tabular}

CK-MB, MB isoenzyme of creatine kinase; MI, acute myocardial infarction; NICP, non-ischaemic chest pain; SAP, stable angina pectoris; UAP, unstable angina pectoris.

sensitivity for cTnT was examined using cut off values for cTnT from $0.01-0.1 \mu \mathrm{g} / \mathrm{l}$ (table 2 ). Reduction in the cut off value resulted in improvement in sensitivity but loss of specificity, with optimal trade off in the range of $0.04-0.06 \mu \mathrm{g} / \mathrm{l}$.

\section{Patients without a primary diagnosis of acute coronary}

\section{syndrome}

Patients with ischaemic heart disease

There were 122 patients with cardiac failure: 56 with congestive heart failure, 49 with arrythmias producing heart failure, and 17 with underlying ischaemic heart disease. cTnT exceeded $0.05 \mu \mathrm{g} / \mathrm{l}$ in $52(45.6 \%)$ of these, and was raised to $0.1 \mu \mathrm{g} / \mathrm{l}$ or above in 28. These data are summarised in fig 3 .

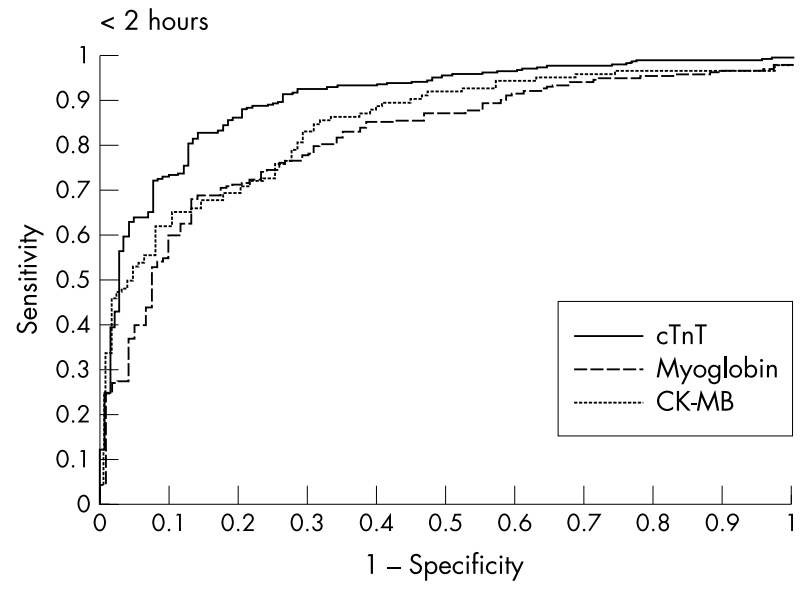

6-12 hours

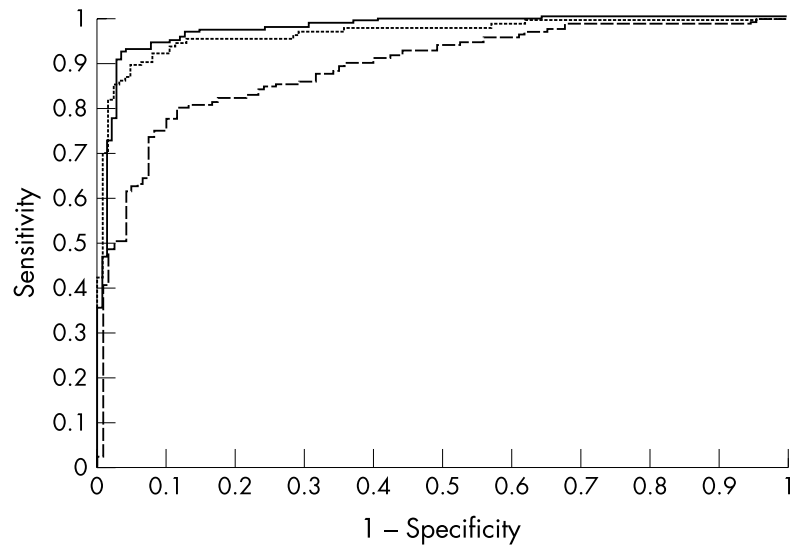

Patients with chest pain without suspected acute coronary syndrome.

In all, 124 patients were admitted with a final diagnosis that excluded suspected acute coronary syndrome as a primary diagnosis. In one there was inadequate documentation so that patient was excluded from further analysis. In 75 , cardiac disease could be categorically excluded (39 with rheumatological disorders, five with carcinoma, 13 with gastrointestinal tract disorders, four with viraemia, and 14 with other miscellaneous diagnoses); cTnT was less than 0.05 $\mu \mathrm{g} / \mathrm{l}$ in all these cases. There were 37 patients with pulmonary disease (10 with pulmonary emboli, 27 with pulmonary interstitial disease). Four of the 10 patients with a pulmonary

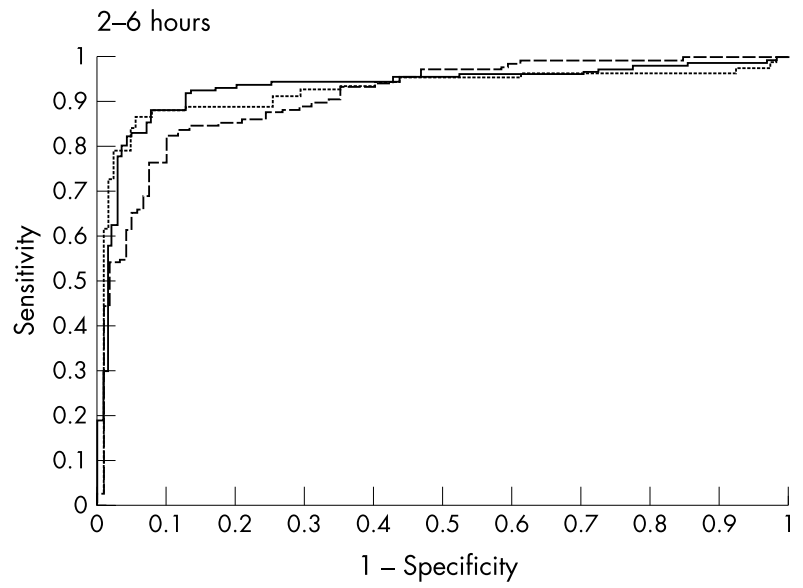

12-24 hours

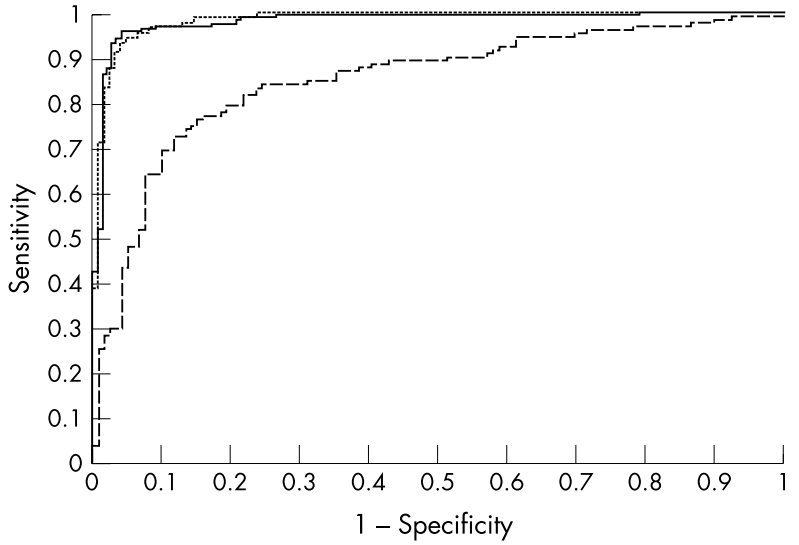

Figure 1 Receiver operating characteristic (ROC) plots of acute myocardial infarction versus stable angina pectoris plus non-ischaemic chest pain according to sample time from admission. 

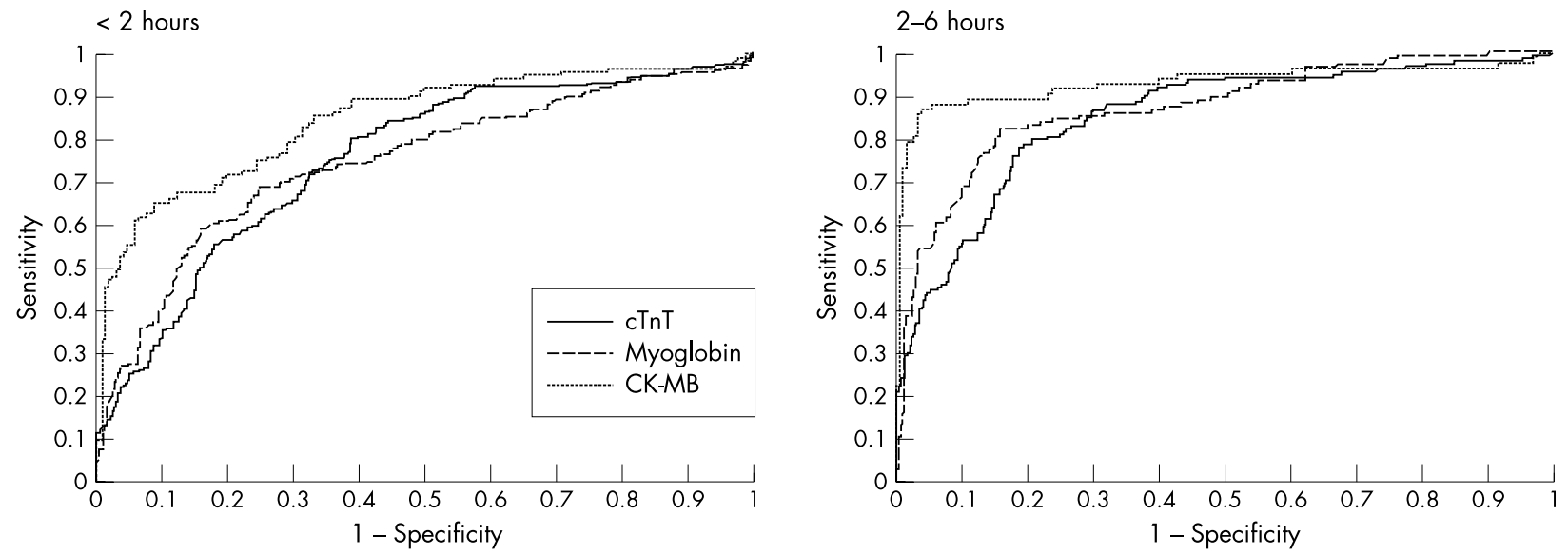

6-12 hours

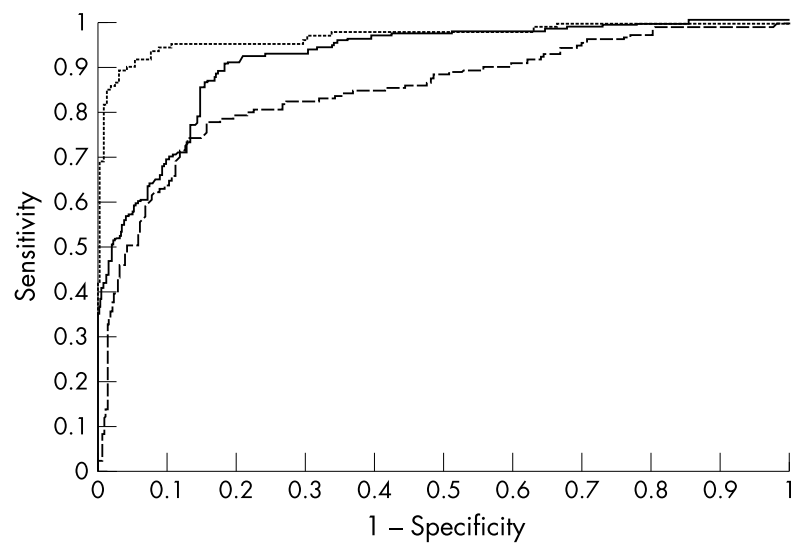

$12-24$ hours

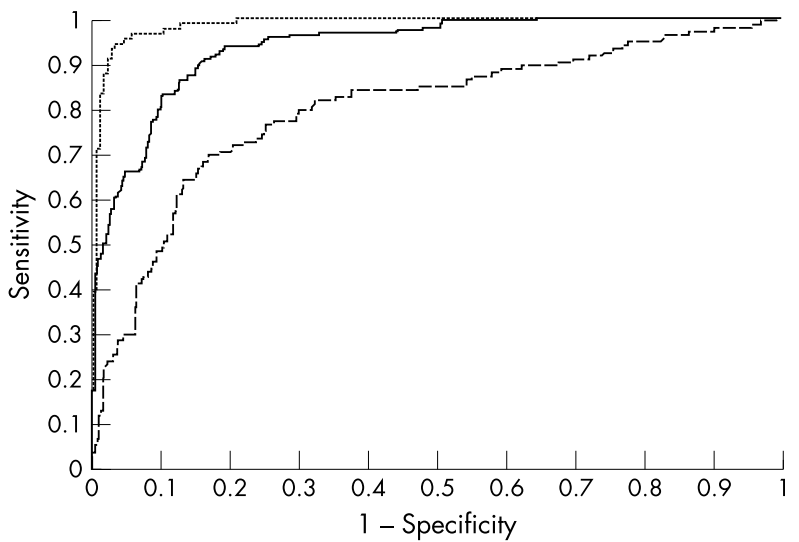

Figure 2 Receiver operating characteristic (ROC) plots of acute myocardial infarction versus stable angina pectoris plus unstable angina pectoris and non-ischaemic chest pain according to sample time from admission.

embolus had a cTnT concentration of $\geqslant 0.05 \mu \mathrm{g} / \mathrm{l}$; in one of these the cTnT value was above $0.1 \mu \mathrm{g} / \mathrm{l}$. Ten of the 27 patients with pulmonary interstitial disease had a cTnT concentration of $\geqslant 0.05 \mu \mathrm{g} / \mathrm{l}$ and in six of these the value exceeded $0.1 \mu \mathrm{g} / \mathrm{l}$. There were two unusual cases—one with thyroiditis and one with systemic lupus erythematosus. In neither of these could myocardial involvement in the primary pathology be excluded. These data are summarised in table 3.
Rhabdomyolysis and multiple trauma

There were 30 patients with rhabdomyolysis. Their creatine kinase values were in the range of 1655-10600 U/l and the cTnT concentration exceeded $0.05 \mu \mathrm{g} / \mathrm{l}$ in two; however, all the cTnT values in these patients were less than $0.1 \mu \mathrm{g} / \mathrm{l}$.

Thirty patients were admitted with multiple trauma: 25 of these had cTnT concentrations less than $0.05 \mu \mathrm{g} / \mathrm{l}$ and two had values above $0.1 \mu \mathrm{g} / \mathrm{l}(0.108$ and $0.129 \mu \mathrm{g} / \mathrm{l})$. Data comparing the markers in patients with multiple trauma are shown fig 4.

\begin{tabular}{|c|c|c|c|c|c|c|}
\hline \multirow{2}{*}{$\begin{array}{l}\text { Time } \\
\text { window } \\
\text { (hours) }\end{array}$} & \multicolumn{6}{|l|}{ Cut off point } \\
\hline & $0.01 \mu \mathrm{g} / \mathrm{l}$ & $0.03 \mu \mathrm{g} / \mathrm{l}$ & $0.04 \mu \mathrm{g} / \mathrm{l}$ & $0.05 \mu \mathrm{g} / \mathrm{l}$ & $0.06 \mu \mathrm{g} / \mathrm{l}$ & $0.1 \mu \mathrm{g} / \mathrm{l}$ \\
\hline \multicolumn{7}{|c|}{ Sensitivity (CI) } \\
\hline 0 & $82.4(74.8$ to 88.6$)$ & 69.5 (60.7 to 77.2$)$ & 67.9 (59.4 to 76.0$)$ & 63.4 (54.5 to 71.5$)$ & $60.3(51.3$ to 68.9$)$ & 53.4 (44.4 to 62.3 ) \\
\hline$>0$ to $<2$ & 99.0 (96.3 to 99.9 ) & 77.5 (71.0 to 83.1$)$ & 73.8 (67.0 to 79.9$)$ & 69.6 (62.5 to 76.0$)$ & 67.5 (60.3 to 74.2$)$ & $60.7(53.6$ to 67.5$)$ \\
\hline 2 to $<4$ & 93.7 (85.8 to 97.9 ) & 83.5 (73.6 to 90.9 ) & 83.5 (73.6 to 90.9$)$ & $82.3(72.2$ to 89.9$)$ & $79.7(69.1$ to 88.0$)$ & $73.4(62.3$ to 82.7$)$ \\
\hline 4 to $<6$ & 94.9 (87.4 to 98.6$)$ & 92.3 (84.0 to 97.1$)$ & 92.3 (84.0 to 97.1$)$ & 91.0 (82.4 to 96.3$)$ & $88.5(79.2$ to 94.6$)$ & 85.9 (76.2 to 92.7$)$ \\
\hline 6 to $<12$ & 97.6 (94.5 to 99.2 ) & 95.7 (92.0 to 98.0 ) & 93.8 (89.7 to 96.7 ) & $93.8(89.7$ to 96.7$)$ & 92.9 (88.5 to 95.9 ) & 92.4 (87.9 to 95.6 ) \\
\hline$\geqslant 12$ & 99.0 (98.0 to 99.6 ) & 96.0 (94.3 to 97.3$)$ & 95.0 (93.1 to 96.5$)$ & 94.9 (93.0 to 96.4 ) & $94.2(92.2$ to 95.8$)$ & 90.7 (88.4 to 92.7 ) \\
\hline \multicolumn{7}{|c|}{ Specificity (Cl) } \\
\hline & $60.0(32.3$ to 83.7$)$ & 73.3 (44.9 to 92.2 ) & 73.3 (44.9 to 92.2 ) & 73.3 (44.9 to 92.2 ) & 73.3 (44.9 to 92.2 ) & 80.0 (51.9 to 95.7$)$ \\
\hline$>0$ to $<2$ & 51.6 (43.5 to 59.6$)$ & 77.4 (70.0 to 83.7 ) & $80.0(72.7$ to 86.1$)$ & 80.6 (73.5 to 86.5$)$ & 82.6 (75.8 to 88.4$)$ & 87.1 (80.7 to 92.0$)$ \\
\hline 2 to $<4$ & 35.9 (21.1 to 52.8$)$ & 71.8 (55.4 to 85.0 ) & 74.4 (58.0 to 87.0 ) & $76.9(60.7$ to 88.9$)$ & 76.9 (60.7 to 88.9$)$ & 89.7 (75.8 to 97.1$)$ \\
\hline 4 to $<6$ & 43.8 (19.8 to 70.1 ) & 68.8 (41.3 to 89.0$)$ & 81.3 (54.4 to 96.0 ) & 81.3 (54.4 to 96.0 ) & $81.3(54.4$ to 96.0$)$ & 81.3 (54.4 to 96.0 ) \\
\hline 6 to $<12$ & 31.0 (19.5 to 44.5 ) & 56.9 (43.3 to 69.8$)$ & 62.1 (48.3 to 74.6 ) & 63.8 (49.9 to 75.9 ) & $67.2(53.7$ to 79.0$)$ & 74.1 (61.1 to 84.7$)$ \\
\hline$\geqslant 12$ & 38.6 (32.4 to 45.1 ) & 56.8 (50.1 to 63.2$)$ & $58.9(52.5$ to 65.1$)$ & 60.6 (54.2 to 66.7$)$ & 63.1 (56.6 to 69.2) & $71.4(65.2$ to 77.0$)$ \\
\hline
\end{tabular}

$\mathrm{Cl}$, confidence interval. 


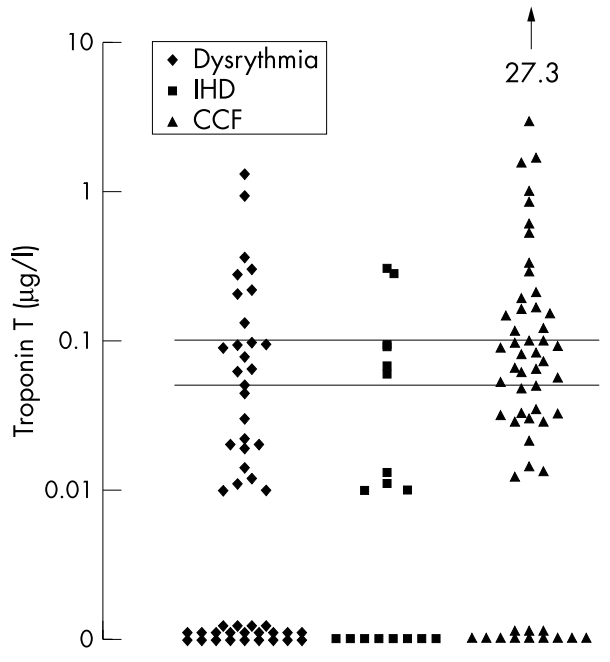

Figure 3 Cardiac markers in heart failure patients.

\section{DISCUSSION}

The results of this study show that a lower diagnostic cut off for CTnT using the third generation assay is appropriate. It also illustrates the flaw in using CK-MB as the gold standard. There is an apparent fall in diagnostic efficiency when a less well defined diagnostic group, unstable angina, is included in the population studied. Test evaluations are typically performed on selected patient populations or on samples collected as part of a clinical trial. The patients involved have a high probability of ischaemic heart disease (typically $>80 \%$ ) and the majority have a clear diagnosis of acute myocardial infarction. In routine clinical practice we found the prevalence of ischaemic heart disease to be $50 \%$, with acute myocardial infarction at presentation in only $10 \%$. The majority of patients required cardiac enzyme measurement for diagnosis. The situation is worse in the emergency department population, where there is a significant incidence of missed acute myocardial infarction. ${ }^{24}$ Realistic evaluation requires usual measurement, an unselected population, cases that are diagnostically challenging, and technology available for routine clinical use.

The diagnostic sensitivity of CK-MB mass for acute myocardial infarction was close to $100 \%$, consistent with the kinetics of $\mathrm{CK}-\mathrm{MB}$ release $\mathrm{e}^{22}$ and its inclusion in the conventional diagnostic classification. In patients with unstable angina, $70 \%$ had detectable cTnT, exceeding $0.1 \mu \mathrm{g} / \mathrm{l}$ in $31.3 \%$. The confounding effect of CK-MB on the diagnostic classification is illustrated by exclusion of patients with unstable angina, when the diagnostic efficiency of cTnT measurement improved. Myoglobin did not prove to be a consistently better marker than CK-MB in the first six hours, and thereafter its performance declined. Myoglobin has been considered to be one of the earliest markers to rise following acute myocardial infarction. However, early studies did not compare myoglobin with sensitive assays for CK-MB mass and

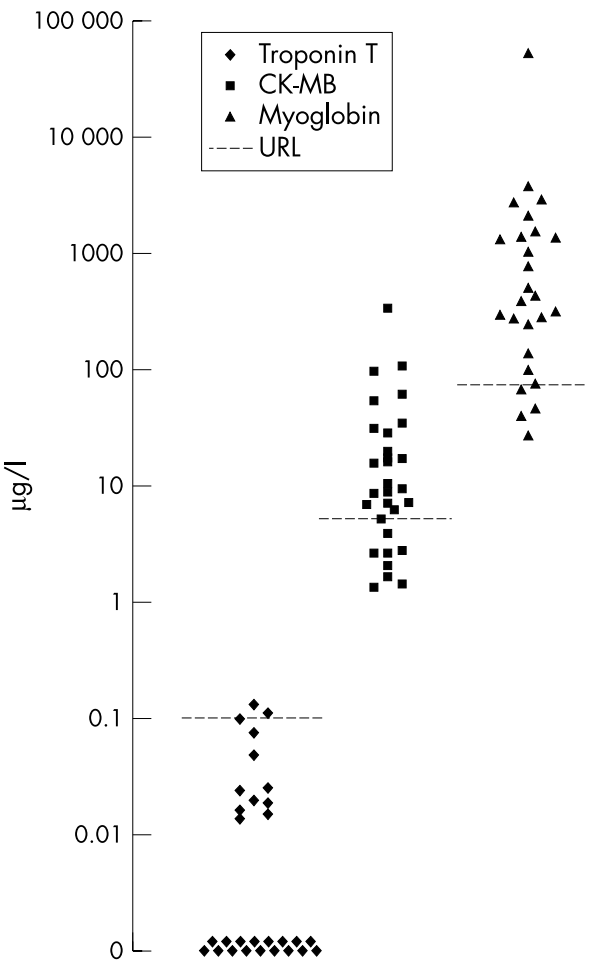

Figure 4 Cardiac markers in patients with multiple trauma.

cTnT. ${ }^{10-12} 25$ The short time window for myoglobin means that early peak values could be missed. Myoglobin is probably useful in the emergency department for early exclusion of myocardial infarction, but is less useful in patients admitted to hospital, as blood samples tend to be taken later.

It has been proposed that the definition of acute myocardial infarction should include cardiac troponins ${ }^{7}$ and that treatment recommendations should be revised accordingly. ${ }^{26}$ Selection of an appropriate cut off point is important. In a "normal" group, cardiac troponins are undetectable. Detailed analysis of the diagnostic cut off point from the ROC data suggested that the value should be reduced to $0.05 \mu \mathrm{g} / \mathrm{l}$ for an unselected patient population. The FRISC study showed that at a value above $0.06 \mu \mathrm{g} / \mathrm{l}$ there is an increased risk of a cardiac event. ${ }^{27}$ Long term follow up of that study group over four years showed a very low event rate at cTnT values less than $0.06 \mu \mathrm{g} / \mathrm{l}^{28}$ A recent study suggested a value of $0.03 \mu \mathrm{g} / \mathrm{l}$ for risk stratification but used highly selected patients in a clinical trial of unstable angina. Recently published data have shown that cTnT values exceeding $0.01 \mu \mathrm{g} / \mathrm{l}$ indicate higher risk in the unstable angina population. ${ }^{29}$ However, cut off points at this level are difficult to measure reliably. There is therefore good evidence to support the use of a cut off value in the range $0.03-0.06 \mu \mathrm{g} / \mathrm{l}$. We feel that a value of $0.05 \mu \mathrm{g} / \mathrm{l}$ is

Table 3 Values for troponin T, myoglobin, and CK-MB in non-cardiac populations

\begin{tabular}{|c|c|c|c|c|}
\hline Disease & $\mathrm{n}$ & Troponin $\mathrm{T}(\mu \mathrm{g} / \mathrm{l})$ & Myoglobin $(\mu \mathrm{g} / \mathrm{l})$ & CK-MB $(\mu \mathrm{g} / \mathrm{I})$ \\
\hline Rheumatoid joint disease & 39 & $<0.01(<0.01$ to 0.041$)$ & 34.4 (25 to 127.0 ) & $0.8 \quad(0.2$ to 6.1$)$ \\
\hline Carcinoma & 5 & $<0.01 \quad(<0.01$ to 0.02$)$ & $41 \quad(30$ to 120$)$ & $1.3 \quad(0.5$ to 5.6$)$ \\
\hline GIT & 13 & $<0.01 \quad(<0.01$ to 0.04$)$ & 58 (38.7 to 147$), n=10$ & 2.1 (1.0 to 7.5$), n=12$ \\
\hline Viraemia & 4 & $<0.01 \quad(<0.01$ to $<0.01)$ & (25 to 77$)$ & $1.4 \quad(0.3$ to 1.4$)$ \\
\hline Pneumonia & 28 & $0.016(<0.01$ to 0.72$)$ & 101 (36 to 3100$), n=26$ & 4.1 (0.3 to 235$), n=25$ \\
\hline PE & 9 & $0.026(<0.01$ to 4.08$)$ & 48.5 (33 to 84$), \quad n=8$ & 1.85 (0.8 to 5.7$), n=8$ \\
\hline Other & 26 & $<0.01 \quad(<0.01$ to 0.27$)$ & $59(28$ to $>3000), n=22$ & $2.5(0.6$ to 72$), n=25$ \\
\hline
\end{tabular}

Values are median (range)

CK-MB, MB isoenzyme of creatine kinase; GIT, gastrointestinal tract disease; PE, pulmonary embolus. 
pragmatically the most appropriate. It is in the range for accurate measurement, useful in the general chest pain population, and consistent with our ROC data. The use of a lower cut off may be more appropriate in patients with a definitive diagnosis of acute coronary syndrome, but further studies are required. Clinical studies have shown that the magnitude of cTnT release is a reflection of the degree of actual or functional myocardial damage. ${ }^{30} 31$ The degree of cTnT release also reflects the degree of risk of a subsequent cardiac event. ${ }^{1617273233}$

In patients with chest pain that was non-cardiac in origin and where cardiac disease could be categorically excluded, no cTnT elevations were seen. In patients with rhabdomyolysis, cTnT was marginally raised if at all, despite substantial elevations of creatine kinase. Elevations of CTnT were only seen where a possibility of myocardial damage existed ${ }^{34}$ or where that would be consistent with data reported elsewhere. ${ }^{35}$ Clearly, cTnT measurements cannot be used uncritically for diagnosis. Elevation of cTnT is pathognomonic of myocardial cell damage, but only in the presence of appropriate clinical or ECG findings does this constitute acute myocardial infarction. The definition of acute myocardial infarction remains clinical, but cTnT is a core diagnostic test. The measurement of cTnT has been shown to identify patients who will benefit from revascularisation, or from low molecular weight heparin and glycoprotein IIb/IIIa antagonists. ${ }^{17} 2936-38$ In order to be clinically useful a rapid and precise cTnT assay is required, with results comparable from both laboratory and point of care testing. These criteria are met by this assay.

\section{Conclusions}

In routine clinical practice, measurement of CTnT by the third generation assay on the 1010 analyser at a diagnostic cut off of $0.05 \mu \mathrm{g} / \mathrm{l}$ allows rapid accurate differential diagnosis of patients with suspected acute coronary syndrome, and of patients with other causes of chest pain. Myoglobin can serve as a useful short term marker but was not superior to CTnT or CK-MB in this study.

\section{ACKNOWLEDGEMENTS}

We would like to thank Dr C Berding and H-D Kraemer for statistical analysis of the data. The study was supported by donation of reagents from Roche Diagnostics.

Participating investigators: M Tichy, J Gregor (Faculty Hospital, Hrades Kralove, Czechien); I Jokl, J Kral (Hospital Na Frantisku, Prague, Czechien); L Uotila, M Mänttäri, H Lappalainen (Meilahti Hospital, Helsinki, Finland); I Penttilä, K Penttilä, T Rantanen (Kuopio University Hospital, Kuopio, Finland); B Hennache (Hospital de Cardiologie, Lille, France); M Rigaud (University Hospital, Limoges, France); A Polge (CMU Laboratoire Central de Biochimie, Nimes, France); B Capolaghi (Hospital Bel Air, Thionville, France); S Samaille (Centre hospitalier de St Omer, St Omer, France); A Alken, W Wölk (Herz-Kreislauf-Klinik, Bad Bevensen, Germany); G Honauer (Krankenhaus Bruchsal, Bruchsal, Germany); G Oremek (Klinikum der Johann Wolfgang Goethe-Universität, Frankfurt, Germany); K Peisker (St-Elisabeth-Krankenhaus, Halle, Germany); B von Eisenhart-Rothe, Albertinen-Krankenhaus, Hamburg, Germany); K Richter, E Briehl (Ferdinand-Sauerbruch-Klinik, Wuppertal, Germany); G Kurta, T Toth (Hospital, Berettyoujfalu, Hungary); G Böcskey, P Valyi (Hospital, Csorna, Hungary); K Horvath, I Szoboszlay, P Botos (County Hospital, Eger, Hungary); L Szep, A Szenkovsky (Hospital, Keszthely, Hungary); I Vamosi, J Stefan (County Hospital, Miskolc, Hungary); A Higginson, D McBride (The Ulster Hospital, Belfast, Ireland); G Gilson (Centre Hospitalie de Luxembourg, Luxembourg, Luxembourg); G Kravdal, T J Ostreng, Central Hospital in Akershus, Nordbyhagen, Norway); W Lysiak-Szydlowska (Zaklad Zywienia Klinicznego, Gdansk, Poland); M Bozek, E Stepien, M Szajna-Zych (Jagiellonian University Hospital, Krakow, Poland); B Andraskova (Nemocnica S Poliklinikov, P Bystrica, Slovakia); A Molcanyiova (University Hospital, Kosice, Slovakia); A Katrincova (Nemocnica S Poliklinikov, Levice, Slovakia); M Farkas (District Hospital, Trebisov, Slovakia); J Vindis (Nemocnica S Poliklinikov, Trencin, Slovakia); J L Marin (Hospital Clinic Barcelona, Barcelona, Spain); R Segura (Hospital Vall d'Hebro, Barcelona, Spain); L Cabrero (Hospital Josep Trueta, Girona, Spain); J Valero (Hospital
Bellvitge, Barcelona, Spain); C Tafalla (Hospital Mostoles, Madrid, Spain); A Gonzales (Clinica Universitaria de Navarra, Pamplona, Spain); F Recio (Hospital Valme, Sevilla, Spain); R Argilaga (Hospital Mutua de Terrassa, Terrassa, Spain); A Martin (Hospital Miguel Servet, Zaragoza, Spain); E Printzen (Inselspital, Bern, Suisse); R Erdmann-Meyer (Regionalspital, Burgdorf, Suisse); K Hansson, O Kastebo, A Lehto (Gällivare Lasarett, Gällivare, Sweden); A Karkianen, U-B Erkstam (Kiruna Lasarett, Kiruna, Sweden); S Smith (Walsgrave General Hospital, Coventry, UK); G McCreanor, P Stubbs (Royal Free Hospital, London, UK); I R Hainsworth, A Fielding (Morriston Hospital, Swansea, Wales, UK).

\section{Authors' affiliations}

P O Collinson, Department of Chemical Pathology, St George's Hospital, London, UK

P J Stubbs, Department of Cardiology, Mayday Hospital, Croydon, UK A-C Kessler, Clinical Evaluation, Roche Diagnostics, Tutzing, Germany

\section{REFERENCES}

1 Yusuf S, Pearson M, Sterry $\mathrm{H}$, et al. The entry ECG in the early diagnosis and prognostic stratification of patients with suspected acute myocardial infarction. Eur Heart J 1984:5:690-6.

2 FTT Collaborative Group. Indications for fibrinolytic therapy in suspected acute myocardial infarction: collaborative overview of early mortality and major morbidity results from all randomised trials of more than 1000 patients. Fibrinolytic therapy trialists' (FTT) collaborative group [see comments and published erratum on $\mathrm{p} 742$ ]. Lancet 1994;343:311-22.

3 Zarling EJ, Sexton H, Milnor P. Failure to diagnose acute myocardial infarction. The clinicopathologic experience at a large community hospital. JAMA 1983;250:1177-81.

4 Brush JE, Brand DA, Acampora D, et al. Use of the initial electrocardiogram to predict in-hospital complications of acute myocardial infarction. N Engl J Med 1985;312:1137-41.

5 McQueen MJ, Holder D, El Maraghi NR. Assessment of the accuracy of serial electrocardiograms in the diagnosis of myocardial infarction. Am Heart J 1983;105:258-61.

6 Nomenclature and criteria for diagnosis of ischemic heart disease Report of the Joint International Society and Federation of Cardiology/World Health Organization task force on standardization of clinical nomenclature. Circulation 1979:59:607-9.

7 Myocardial infarction redefined - a consensus document of the Joint European Society of Cardiology/American College of Cardiology committee for the redefinition of myocardial infarction. Eur Heart 2000;21:1502-13.

8 Panteghini M, Apple FS, Christenson RH, et al. Proposals from IFCC Committee on Standardization of Markers of Cardiac Damage (C-SMCD): recommendations on use of biochemical markers of cardiac damage in acute coronary syndromes. Scand J Clin Lab Invest Suppl 1999:230:103-12.

9 Wu AH, Apple FS, Gibler WB, et al. National Academy of Clinical Biochemistry Standards of Laboratory Practice: recommendations for the use of cardiac markers in coronary artery diseases. Clin Chem 1999;45: 1104-21

10 Roxin LE, Venge $P$, Friman $G$, et al. Radioimmunoassays of human myoglobin in serum and urine. Scand J Clin Lab Invest 1979;39:37-46.

11 Roxin LE, Venge P, Wide L. A fast and sensitive radioimmunoassay of human myoglobin for use in the early diagnosis of heart infarction. Clin Chim Acta 1980;107: 129-34.

12 Roxin LE, Cullhed I, Groth T, et al. The value of serum myoglobin determinations in the early diagnosis of acute myocardial infarction. Acta Med Scand 1984;215:417-25.

13 Gerhardt W, Katus H, Ravkilde J, et al. S-troponin T in suspected ischemic myocardial injury compared with mass and catalytic concentrations of S-creatine kinase isoenzyme MB. Clin Chem 1991;37:1405-11.

14 Hamm CW, Ravkilde J, Gerhardt W, et al. The prognostic value of serum troponin T in unstable angina. N Engl J Med 1992;327: 146-50.

15 Collinson PO. Troponin T or troponin I or CK-MB (or none?). Eur Heart J 1998:19/suppl N):N16-24.

16 Stubbs P, Collinson P, Moseley D, et al. Prognostic significance of admission troponin $T$ concentrations in patients with myocardial infarction. Circulation 1996;94:1291-7.

17 Stubbs P, Collinson P, Moseley D, et al. Prospective study of the role of cardiac troponin $T$ in patients admitted with unstable angina. BM 1996;313:262-4.

18 Lee TH, Goldman L. Serum enzyme assays in the diagnosis of acute myocardial infarction. Recommendations based on a quantitative analysis. Ann Intern Med 1986;105:221-33.

19 Leung FY, Galbraith LV, Jablonsky G, et al. Re-evaluation of the diagnostic utility of serum total creatine kinase and creatine kinase-2 in myocardial infarction [published errata appear in vol 35, p 2257 and vol 36, p 1990]. Clin Chem 1989;35:1435-40.

20 Werner M, Brooks SH, Mohrbacher RJ, et al. Diagnostic performance of enzymes in the discrimination of myocardial infarction. Clin Chem 1982;28:1297-302. 
21 Mair J, Artner-Dworzak E, Dienstl A, et al. Early detection of acute myocardial infarction by measurement of mass concentration of creatine kinase-MB. Am J Cardiol 1991;68:1545-50.

22 Collinson PO, Rosalki SB, Kuwana T, et al. Early diagnosis of acute myocardial infarction by CK-MB mass measurements. Ann Clin Biochem 1992:29:43-7.

23 Ross SM, Fraser CG. Biological variation of cardiac markers: analytical and clinical considerations. Ann Clin Biochem 1998;35:80-4.

24 Collinson PO, Premachandram S, Hashemi K. Prospective audit of incidence of prognostically important myocardial damage in patients discharged from emergency department. BM 2000;320:1702-5.

25 Kubasik NP, Guiney W, Warren K, et al. Radioimmunoassay of serum myoglobin: evaluation and modification of a commercial kit and assessment of its usefulness for detecting acute myocardial infarction. Clin Chem 1978:24:2047-9.

26 Bertrand ME, Simoons ML, Fox KA, et al. Management of acute coronary syndromes: acute coronary syndromes without persistent ST segment elevation. Recommendations of the task force of the European Society of Cardiology. Eur Heart J 2000;21:1406-32.

27 Lindahl B, Venge P, Wallentin L. Relation between troponin T and the risk of subsequent cardiac events in unstable coronary artery disease. The FRISC study group. Circulation 1996;93:1651-7.

28 Lindahl B, Toss H, Siegbahn A, et al. Markers of myocardial damage and inflammation in relation to long-term mortality in unstable coronary artery disease. FRISC study group (Fragmin during instability in coronary artery disease). N Engl J Med 2000;343: 1 139-47.

29 Cannon CP, Weintraub WS, Demopoulos LA, et al. Comparison of early invasive and conservative strategies in patients with unstable coronary syndromes treated with the glycoprotein $\mathrm{llb} / \mathrm{Illa}$ inhibitor tirofiban. N Engl J Med 2001;344:1879-87.

30 Wagner I, Mair J, Fridrich L, et al. Cardiac troponin T release in acute myocardial infarction is associated with scintigraphic estimates of myocardial scar. Coron Artery Dis 1993;4:537-44.
31 Rao AC, Collinson PO, Canepa-Anson R, et al. Troponin T measurement after myocardial infarction can identify left ventricular ejection of less than $40 \%$. Heart 1998;80:223-5.

32 Newby LK, Christenson RH, Ohman EM, et al. Value of serial troponin T measures for early and late risk stratification in patients with acute coronary syndromes. The GUSTO-lla investigators. Circulation 1998;98:1853-9.

33 Ohman EM, Armstrong PW, Christenson RH, et al. Cardiac troponin T levels for risk stratification in acute myocardial ischemia. GUSTO-IIA investigators. N Engl J Med 1996;335:1333-41.

34 Ooi DS, Isotalo PA, Veinot JP. Correlation of antemortem serum creatine kinase, creatine kinase-MB, troponin I, and troponin T with cardiac pathology. Clin Chem 2000;46:338-44.

35 James P, Ellis CJ, Whitlock RM, et al. Relation between troponin T concentration and mortality in patients presenting with an acute stroke: observational study. BM 2000;320:1502-4.

36 Lindahl B, Venge P, Wallentin L. Troponin T identifies patients with unstable coronary artery disease who benefit from long-term antithrombotic protection. Fragmin in unstable coronary artery disease (FRISC) study group. J Am Coll Cardiol 1997;29:43-8.

37 Hamm CW, Heeschen C, Goldmann B, et al. Benefit of abciximab in patients with refractory unstable angina in relation to serum troponin $T$ levels. c7E3 Fab Antiplatelet therapy in unstable refractory angina (CAPTURE) study investigators [see comments and published erratum in vol 341, p 548]. N Engl J Med 1999;340:1623-9.

38 Heeschen C, Hamm CW, Goldmann B, et al. Troponin concentrations for stratification of patients with acute coronary syndromes in relation to therapeutic efficacy of tirofiban. PRISM study investigators. Platelet receptor inhibition in ischemic syndrome management. Lancet 1999;354:1757-62.

\section{IMAGES IN CARDIOLOGY}

\section{Left circumflex coronary artery arising as a terminal extension of the right coronary artery} 61 year old man presented with a history of chest pain of chest pain had started to increase recently and was associated with shortness of breath at rest. There was no history of hyperlipidaemia and cigarette smoking. The patient was taking aspirin, a diuretic, an angiotensin converting enzyme inhibitor, digitalis, nitrates, and mexiletine. On examination his blood pressure was $130 / 80 \mathrm{~mm} \mathrm{Hg}$ and pulse rate 80 beats/min. slightly harsh vesicular breathing in the lower zone. A chest $x$ ray showed cardiomegaly, and ECG revealed atrial fibrillation with left ventricular hypertrophy; in the strip trace a few ventricular extrasystoles were seen. Biochemical investigation revealed only hyperlipidaemia with no other pathology. Echocardiography showed that the left ventricular internal diameters were dilated $(79 \mathrm{~mm} / 57 \mathrm{~mm})$; ejection fraction was $51 \%$, and a third degree mitral insufficiency was evident. Radionuclide ventriculography was subsequently undertaken which
A 13 years' duration. The frequency and severity of the Auscultation revealed a mild systolic murmur on the apex, with

showed significant hypokinesia in the septum and an ejection fraction of $20 \%$.

The patient was admitted and coronary arteriography and ventriculography undertaken. Coronary arteriography showed a normal left anterior descending coronary artery, but in the circumflex $(\mathrm{Cx})$ region neither normal vascular structure nor collateral circulation was evident, suggesting $\mathrm{Cx}$ occlusion (below left). Upon selective right coronary arteriography, the $\mathrm{Cx}$ artery arose as a terminal extension of the right coronary artery, supplying the Cx region; however, no stenosis was seen (below right). Left ventriculography showed diffuse hypokinesia. The patient was transferred to surgery for mitral valve replacement because of severe left ventricular dysfunction; however, the operation was cancelled and the patient was treated medically.

\section{O Sagkan \\ $M$ Yazici \\ $S$ Demircan} demircan76@hotmail.com
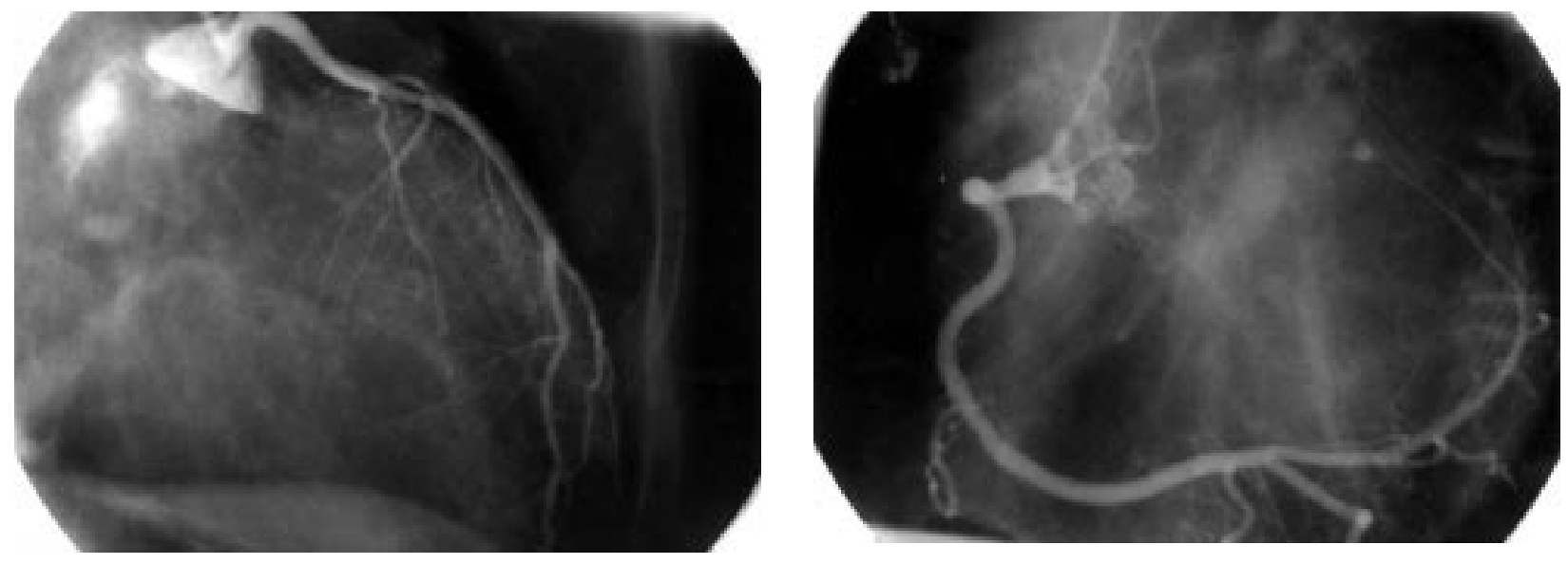